\section{Moving on from euthanasia}

It is time to move on from the euthanasia debate. ${ }^{1}$ Let's also move on from "physician-assisted suicide."

Rationally, if a society legalizes the killing of sick people, it should use the group that is most efficient, legal, trained and, at times, paid to kill: the Armed Forces. Want to die? Fill out a chit, and the sniper takes you out from 100 yards. No pain; indeed, you will never even hear the shot. Still in the hospital? Perhaps nerve gas in the oxygen line. Very effective. Some options are a bit messy, and therein lies the rub. The hypocrites want everything all "nice" and sanitized.

The Armed Forces will kick and scream about killing the population they are sworn to serve. So please, tell me why physicians should do it instead.

\section{Kevin M. Hay}

Wainwright Health Centre, Wainwright, Alta.

\section{REFERENCE}

1. Flegel K, Hébert PC. Time to move on from the euthanasia debate. CMAJ 2010;182:877.

For the full letter, go to: www.cmaj.ca/cgi/eletters /182/9/877\#539735

DOI: 10.1503/cmaj.110-2093

What a mindless comment. Flegel and Hébert's editorial directs that "As physicians, we should ... avoid further polarization of this important debate with our own values and ideologies." Flegel and Hébert don't seem to realize that they have just injected their own values into the debate by insisting that, in their personal opinion, only impersonal values have merit! Of course, this is central to the very issue being discussed; whether a specific value happens to be one's own is clearly separate from its relative merit.

Most of us share the authors' desire for honest dialogue, education and engagement. However, trying to muzzle physicians from anything beyond the physiology and basic science of dying, as the authors seem to imply, is an affront to the whole of medicine. Clinical care benefits from continual investi- gation, testing and discussion by physicians across the whole range of human experience. Those who spout paternalistic injunctions against personal values and ideologies artificially close discussion and polarize with values and ideologies all their own.

\section{Shawn D. Whatley MD \\ Mount Albert, Ont.}

\section{REFERENCE}

1. Flegel K, Hébert PC. Time to move on from the euthanasia debate. CMAJ 2010;182:877.

For the full letter, go to: www.cmaj.ca/cgi/eletters /182/9/877\#574006

DOI: 10.1503/cmaj.110-2096

\section{Legislation protects the vulnerable?}

Chambaere and colleagues describe a decrease in the rate of life-ending acts without explicit request (LAWER) and an increase in the rate of euthanasia since legalization of euthanasia in Belgium. ${ }^{1}$ Given this coincidental rise and fall, I propose that legalization has converted instances that would previously have been life-ending acts without explicit request into euthanasia. Instead of performing life-ending acts without explicit request while believing their patients wanted euthanasia, physicians now feel able to explicitly discuss the issue without fear of prosecution.

The data presented by Chambaere and colleagues support this hypothesis. As the authors mention, in 2007, the characteristics of patients receiving lifeending acts without explicit request were dissimilar to those of euthanasia patients: the former were older $(53 \%$ over the age of 80), nearer the end of their lives and less likely to have cancer (34\%). However, data collected in 2001, before legalization of euthanasia, did not show this clear separation of characteristics between the two groups of patients (e.g., only $24 \%$ of patients receiving life-ending acts without explicit request were over age 80 , and $52 \%$ had cancer). This supports the idea that before legalization, some patients who may have wanted euthanasia were receiving life-ending acts without explicit request because communication between physician and patient was not explicit. If this is true, it's an example of a protective function of regulation.

\section{Ilana R. Levene}

Keble College, Oxford, UK

\section{REFERENCES}

1. Chambaere K, Bilsen J, Cohen J, et al. Physicianassisted deaths under the euthanasia law in Belgium: a population-based survey. CMAJ 2010;182: 895-901.

2. Rietjens JA, Bilsen J, Fischer S, et al. Using drugs to end life without an explicit request of the patient. Death Stud 2007;31:205-21.

For the full letter, go to: www.cmaj.ca/cgi/eletters /182/9/895\#523111

DOI: $10.1503 / \mathrm{cmaj} .110-2092$

\section{Assisted death without consent?}

The recent article by Inghelbrecht and colleagues $^{1}$ has led to startling interpretations in the media of unethical practice by Belgian nurses involved in palliative care. Assisted death without patient consent, runs the theme.

The study shows that medical decisions were made without the patient's explicit request, but it is vague on the role of the decision-makers choosing for the patient. The appendices to the article are only suggestive: Why does the flow chart not show the response to question 10.7 (i.e., whether discussion with relatives had occurred)? Also, the article shows in tabular form that, of the "unexplicitly requested" assisted deaths, nurses discussed the patient's or relatives' wishes in $41 \%$ of cases when they were involved in decision-making. Why is this not mentioned in the text? In the other cases, was the physician involved? Or others? The nurse answering the questionnaire may not have known, but the interpretation seems to be that no discussion was held.

The article makes several important supported claims that describe evasion or overlooking of the law and policy, but the most startling suggestion - that 